http://jmscr.igmpublication.org/home/ ISSN (e)-2347-176x ISSN (p) 2455-0450 crossref DOI: https://dx.doi.org/10.18535/jmscr/v7i8.19

Journal Of Medical Science And Clinical Research

\title{
Primary Tubercular Mastoiditis with post aural abscess: A rare presentation in Subhimalayas
}

Authors

\section{Dr Disha Sharma ${ }^{1 *}$, Dr Pankaj Chauhan ${ }^{2}$, Dr Vineeta Sharma ${ }^{3}$}

${ }^{1}$ Medical Officer, Department of Oto-Rhino-Laryngology, Dr.Radha Krishnan Govt. Medical College Hamirpur, HP, India

${ }^{2}$ Junior Resident, Department of Oto-Rhino-Laryngology, Indira Gandhi Medical College, Shimla, HP, India

${ }^{3}$ Assistant Professor, Microbiology, Indira Gandhi Medical College, Shimla

*Corresponding Author

Dr Disha Sharma

Medical Officer Specialist (Otorhinolaryngology) Dr Radhakrishnan Govt. Medical College, Hamirpur, HP

\begin{abstract}
In India 15-20\% of all the tuberculosis cases are extrapulmonary. The rarity of tubercular otitis media makes it an entity often missed while making diagnosis. We present a case of seven year old female child presenting with ear discharge, earache and post-aural swelling. HRCT temporal bone showed opacity of the mastoid antrum and soft tissue collection in the retro-auricular area. CBNAAT detected mycobacterium tuberculosis from the pus drained from the mastoid antrum.
\end{abstract}

Keywords: Tubercular otitis media, CBNAAT, mastoid antrum, post-aural swelling.

\section{Introduction}

Tubercular mastoiditis is a type of silent tubercular mastoiditis as there is no history of ear discharge and normal tympanic membrane hearing. There is no history suggestive of any tubercular foci elsewhere in the body. ${ }^{[1]}$ Tubercular otitis media is mostly secondary to spread of infection from lungs. The route of infection is from eustachian tube, perforated tympanic membrane and hematogenous spread. ${ }^{[2]}$ The most common sites of extra-pulmonary tuberculosis are lymph nodes $(34.4 \%)$, pleural effusion $(25.2 \%)$, abdominal $(12.8 \%)$ and central nervous system $(9.4 \%){ }^{[3]}$ In case of tubercular otitis media complications occur mostly when the diagnosis is delayed including facial paralysis, labyrinthitis, meningitis and sub-periosteal abscess. $^{[4]}$

\section{Case Report}

A 7 year old female child presented to the OPD of a tertiary care centre of subhimalayas with postaural swelling right side for two weeks. There was history of ear discharge for two weeks which was not responding to topical and systemic antibiotics and pain for three days. There was no history of trauma or any surgery. No history of fever, loss of appetite or loss of weight and no history of contact .On local examination left ear was normal while right ear pinna was pushed anteriorly and inferiorly, preauricular region was normal. A swelling of $4 * 4 \mathrm{~cm}$, tender and fluctuant was 
present over the post-aural region. Post-aural sulcus was obliterated and ironed out mastoid was seen. Otoscopic examination showed sagging of posterior meatal wall. On cleaning the discharge present in the external auditory canal, pus was seen oozing out from the centre of tympanic membrane. Blood investigations were done. Haemoglobin was $10.3 \mathrm{gm} / \mathrm{dl}$, WBC -9.6 thousand/microliter, ESR was $65 \mathrm{~mm}$ at first hour. $\mathrm{X}$-Ray chest and Montoux test were normal. High resolution computed tomography of temporal bone showed soft tissue opacity in the mastoid antrum suggestive of destruction of the mastoid air cells on the right side and soft tissue collection in retro-auricular region measuring $5 * 5 \mathrm{~cm}$ .(Image1) Ossicular chain appeared to be intact. Patient was taken up for cortical mastoidectomy right ear. Intra-operatively there was dehiscence of lateral cortical wall, 6-8ml pus was drained from the mastoid antrum which was sent for culture and sensitivity, AFB staining and CBNAAT. Sinodural angle including sinus plate and dural plate were intact. Culture and AFB staining were negative while CBNAAT detected Mycobacterium tuberculosis. Anti-tubercular therapy was started and given for six months. The patient was asymptomatic at 7 months follow-up.

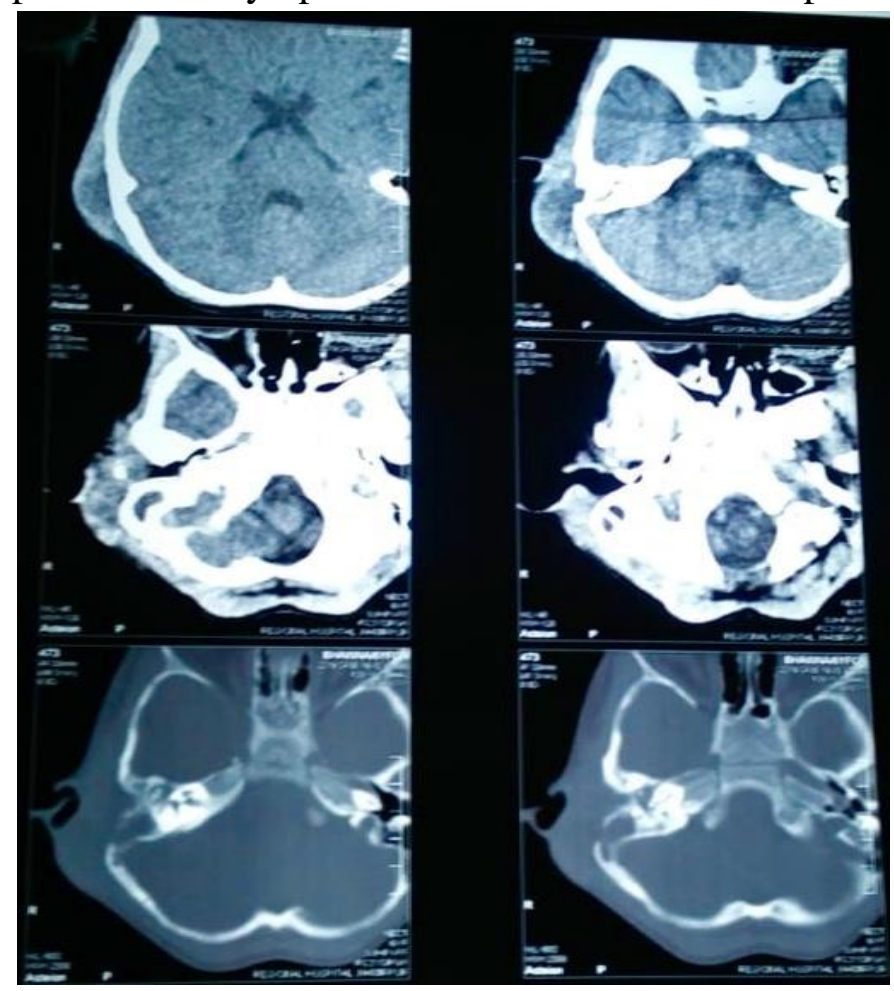

\section{Discussion}

Tuberculous Otitis media is a rare entity which presents as multiple perforations of tympanic membrane, odourless otorrhoea and pre-auricular lymphadenopathy. It is mostly associated with Pulmonary tuberculosis and may lead to complications like facial nerve paralysis and sensory-neural hearing loss. ${ }^{[5]}$ Due to similarity in symptoms and signs of non-tubercular chronic otitis media and tubercular otitis media there are possibility of missing the diagnosis. According to some studies the percentage of tubercular otitis media is 0.05 to $0.9 \% .{ }^{[4]}$ Tubercular middle ear infections are usually secondary to pulmonary tuberculosis, spread is either haematogenous, through Eustachian tube or tympanic membrane. ${ }^{[1]}$ In a case reported by Kim et al the cause of tubercular Otitis media was due to insertion of tympanostomy tube. ${ }^{[2]}$

GeneXpert and AFB smear microscopy have similar specificity, but sensitivity is much higher in case of GeneXpert. Although culture is the gold standard but it is time consuming taking weeks for detection, moreover simultaneously Rifampicin resistance can't be detected. ${ }^{[6]}$ Micro-organisms interfere with the koch's bacillus, this is considered to be the reason for less sensitivity of bacteriological investigations. ${ }^{[8]}$ According to Cho et al, in case of tubercular otitis media, computed tomography scan of mastoid will commonly show destruction of cortical bone whereas in nontubercular otitis media sclerotic changes are more commonly seen. ${ }^{[8]}$ Even in the absence of pulmonary tuberculosis high index of suspicion is required as it is difficult to detect AFB in the ear discharge as the positivity is $5-35 \%$ only. ${ }^{[9]}$

In our patient there was no history of pulmonary tuberculosis or any history of contact, also the patient had presented with a short history of ear discharge of two weeks only, which was not responding to topical or oral antibiotics .Patient presented with mastoiditis and post aural abscess and diagnosis was made post operatively after mastoidectomy by GeneXpert. ATT should be started as soon as diagnosis is made to prevent 
intracranial and extracranial complications of otitis media like facial nerve palsy, mastoiditis, labrynthitis, and meningitis.

\section{Conclusion}

Making diagnosis of primary tubercular mastoiditis is difficult because of many reasons. Being a rare disease, it is not often suspected, symptoms are variable and the bacteriological culture is negative most of the times as it was in our case also. Patient with ear discharge not responding to conventional treatment should be investigated for tuberculosis in Indian setup and the treatment should be started early.

\section{Sources of support: None}

\section{References}

1. Ravi kumar A, Senthil K, Prasanna Kumar S, Gopinath, Gaurav Bambha (2007) primary tubercular mastoiditis-a rare presentation. Sri Ramachandra Journal of Medicine.

2. Kim, Chang; Jin, Jae; Rho, Young-Soo, Tuberculous otitis media developing as a complication of tympanostomy tube insertionEuropean Archives of OtoRhinoLaryngology, Volume 264, Number 3, March 2007, pp. 227-230(4)

3. Cherian JJ, Lobo I, Sukhlecha A, et al. Treatment outcome of extrapulmonary tuberculosis under Revised National Tuberculosis Control Programme. Indian J Tuberc. 2017;64:104-108.

4. Gupta N, Dass A, Goel N, Tiwari S. Tuberculous Otitis Media Leading to Sequentialib Bilateral Facial Nerve Paralysis. Iran J Otorhinolaryngol. 2015;27(80):231-237.

5. Shankar Tati, Manish Kumar, Benjamin R. Kumar, A. V. S. Hanumantha Rao, Yugandhar. "Primary Tuberculosis Otitis Media: Case Presentation and Review of Literature". Journal of Evolution of
Medical and Dental Sciences 2014; Vol. 3, Issue 74, December 29; Page: 1558015588 ,

6. Agrawal M, Bajaj A, Bhatia V, Dutt S. Comparative Study of GeneXpert with ZN Stain and Culture in Samples of Suspected Pulmonary Tuberculosis. J Clin Diagn Res. 2016;10(5):DC09-DC12. doi:10.7860/JCDR/2016/18837.7755.

7. Cho YS, Lee HS, Kim SW, Chung KH, Lee DK, Koh WJ, et al. Tuberculous Otitis Media: Two Case Reports and Literature Review. ENT: Ear, Nose and Throat. 2002; 81:792-794.

8. Mercêdes Fabiana Araújo, Thaís Gonçalves Pinheiro, Igor Teixeira Raymundo, Vítor Yamashiro Rocha Soares, Pedro Ivo Machado Araújo, Ricardo Luiz de Melo Martins,Carlos Augusto Costa P Oliveira. Tuberculous Otitis Media. Int. Adv. Otol. 2011; 7:(3) 413-417

9. Manju Mahajan, D.S. Agarwal, N.P. Singh and DJ. Gadre, tuberculosis of the middle ear - a case report, Ind. J. Tub., 1995, 42, 558. 